\title{
ELECTROSTATIC MICROACTUATORS WITH INTEGRATED GEAR LINKAGES FOR MECHANICAL POWER TRANSMISSION
}

\author{
Rob Legtenberg, Erwin Berenschot, Miko Elwenspoek and Jan Fluitman
}

\author{
MESA Research Institute, University of Twente, P.O. Box 217, 7500 AE Enschede, \\ The Netherlands
}

\begin{abstract}
In this paper a surface micromachining process is presented which has been used to fabricate electrostatic microactuators that are interconnected with eachother and linked to other movable microstructures by integrated gear linkages. The gear linkages consist of rotational and linear gear structures and the electrostatic microactuators include curved electrode actuators, comb drive actuators and axial gap wobble motors. The micromechanical structures are constructed from polysilicon. Silicon dioxide has been used as a sacrificial layer and silicon nitride was used for electrical insulation. A cyclohexane freeze drying technique is used to prevent problems with stiction. The actuators, loaded with various mechanisms, have been driven successfully by electrostatic actuation. The work is a first step towards mechanical power transmission in micromechanical systems.
\end{abstract}

\section{INTRODUCTION}

With improving performance and fabrication techniques, micromechanical actuators are merging into the field of mechanical power transmission for driving purposes. Previously it has been shown that multi-level linkages can be fabricated by dissolved wafer, bond and assembly techniques [1]. Two silicon wafers are successively processed, aligned and bonded to a glass wafer, and then dissolved in EDP to free micromechanical mechanisms. Other examples of assembled devices that transfer mechanical power are magnetic micromotors where Permalloy and PMMA parts are fabricated with sacrificial LIGA techniques which are subsequently assembled with submicron tolerances [2]. Also axial gap wobble motor have been fabricated from electroplated nickel rotors that were coupled to miniature pinion and gear trains using assembling techniques [3].

Devices where mechanical linkages have been integrated with actuator fabrication are vibromotors where a slider is driven by oblique impact of resonant comb structures [4], and a comb-drive based microengine where the linear motion of comb structures is converted into a rotary motion of an output gear by connecting rods [5]. These latter processes have the advantage of a batch fabrication without the need for assembly of multiple wafers requiring alignments, bonding etc., or the addition of other separately fabricated parts.
In this paper a fabrication process is presented where different types of surface micromachined electrostatic actuators are fabricated in one process which are interconnected and linked to other microstructures using gear mechanisms without the need for assembling techniques. In our previous work several electrostatic actuators that can generate relatively large forces, torques and displacements have been developed and fabricated using surface micromachining techniques. Examples are bi-stable curved electrode actuators [6], linear comb drive actuators [7] and axial gap wobble motors [8]. Mechanisms include gear trains, linear gear racks, sliders and spring structures. First experimental results have shown operational actuators and functional micromechanisms. For example electrically powered micromotors drive gear trains and gear racks. In the latter case a transformation of rotational into linear motion is obtained.

The fabrication process can be used to study and optimise properties of micromechanical gear mechanisms and measure output force or torque of electrostatic actuators. Examples are devices for measurements on static and dynamic friction of gear linkages and measurement of micromotor output torque.

\section{DESIGN ISSUES}

General design issues:

Since the fabrication of the comb drive actuators and curved electrode actuators is relatively simple and can be done in a one mask fabrication process, [6,7] this process has been merged into the fabrication process of the axial gap wobble motor [8]. The micromechanical structures are constructed from polysilicon. Silicon dioxide has been used as a sacrificial layer and silicon nitride was used for electrical insulation. A cyclohexane freeze drying technique is used to prevent problems with stiction.

The operation principle of a lower stator axial gap wobble motor is based on an inclined rotor that is supported at its center and rolling on its outer radius. Excitation of stator poles results in an axial rocking motion of the rotor. This rocking motion is transformed into a rotational motion because of a small difference in the radius of the rotor and its resultant contact point circle at the stator poles. 
In contrast to polysilicon side drive motors, where stator poles are surrounding the rotor, the stator poles of the axial gap wobble motor are located underneath the rotor. This results in a large torque generation because of a large rotor to stator overlap and a readily accessible rotor for mechanical power take off. For a more detailed description of the axial gap wobble motors reference is made to [8].

Because the rotor of the axial-gap wobble motor makes an axial rocking motion and is rolling on its outer radius some adjustments are necessary when external gear teeth are added. By an additional etch step a circular reduction is created in the rotor structure. Now, the rotor will roll on this circular reduction and can have an arbitrary outline. The rotor and gears can rotate and rock in axial directions using a ball bearing while for linear movements a slider bearing was applied using slots that are etched into the silicon wafer. The motor rocking motion places a constraint on the thickness of the gears and therefore the gear thickness should be larger than two times the thickness of the sacrificial layer below it. In our fabrication process a sacrificial layer thickness of about $2 \mu \mathrm{m}$ and a gear thickness of about $6 \mu \mathrm{m}$ was used.

\section{Tooth design:}

Gears are an efficient way to transmit mechanical power at almost any speed ratio desired. Parallel axis gears transmit power with greater efficiency than any other form of gearing. The most common type of gear is the spur gear which has teeth on the outside of a cylinder which are parallel to the cylinder axis. This type of gear can relatively easy be fabricated using anisotropic etching techniques.

A conjugate tooth shape is needed in order to transform motion with constant angular velocity. Involute and cycloidal tooth shapes are conjugate tooth profiles. However cycloid gearing requires center distances to be maintained in order to obtain conjugate action where involute profiles maintain conjugate action even with variations in gear center distances [9].

The gear ratio is a constant and can be found from the ratio of gear teeth numbers. It can be applied for all types of gears with conjugate and non-conjugate gear tooth surfaces and corresponds to the ratio between the gear revolutions. Only in case of conjugate tooth profiles the velocity ratio is equal to the gear ratio. If not, the gears transform rotation with a varying instantaneous velocity ratio.

In this first approach no optimisation has been done on gear design. Because of limitations in our present mask layout program and pattern generator gear teeth with a trapezoidal shape have been used. This will negatively affect the performance of our gears. However, at this stage, main goal is the development of a fabrication process for integrated electrostatic actuators and gear linkages and demonstrate the feasibility of these micromechanical gear linkages in order to transfer mechanical power.

In our design two different gears has been used. The largest gear has 36 teeth and a base radius of 100 $\mu \mathrm{m}$ which also forms the rotor of electrostatic axial gap wobble motors. Smaller gears have 18 teeth and a base radius of $50 \mu \mathrm{m}$. The total depth of the gear teeth is $11 \mu \mathrm{m}$, the thickness is $6 \mu \mathrm{m}$ and a pressure angle of 20 degrees has been used. In order to ensure proper patterning and etching a minimum clearance of $2 \mu \mathrm{m}$ between engaged gear teeth and a bearing clearance of $1 \mu \mathrm{m}$ has been used. As a result, gear backlash will be relatively large.

\section{FRICTION AND WEAR}

Although some work has been done on aspects like friction, wear and lubrication of micromechanisms [10-15], many issues with regard to tribological properties, design and operation of microsystems are yet unexplored and need to be investigated. Frictional effects should be minimised by a proper bearing design and a suitable gear tooth profile set resulting in a, lateral, pure rolling motion between gear teeth. The use of low friction materials $[12,13]$ and lubricants [14] seem to be promising applications. However, it should be kept in mind that the operation of axial gap wobble motors is based upon friction between the rotor and stator surface.

The lifetime of gears and micromotors is limited by wear $[8,10,11]$. Friction and wear studies using specimen-on disc $[12,15]$ have been performed and indicated that diamond-like carbon is an attractive material with respect to friction and wear properties. The wear mechanism of brittle materials like DLC, $\mathrm{SiO}_{2}, \mathrm{Si}_{3} \mathrm{~N}_{4}$ and SCS was found to be dominated by asperity fracture, and wear of polysilicon is dominated by asperity deformation [15]. In general wear has been found to follow macroscopic theory where materials of highest hardness show the lowest wear rates and wear rate is dependent on contact pressure.

A problem related to the axial gap wobble motor is that the rocking motion of the rotor gives rise to axial motions between the rotor teeth and the teeth of the gear structure that is driven. This will induce additional frictional forces. The normal force at the tooth surfaces is roughly equal to the excess motor torque divided by the rotor radius. The torque of a motor with a radius of $100 \mu \mathrm{m}$ can theoretically be in the range of $\mathrm{nNm}$, at high electrostatic fields [8], leading to normal forces in the $10 \mu \mathrm{N}$ range. The axial frictional force resulting from the rocking motion is a fraction of this normal force after multiplication by the frictional coefficient of the materials in contact (e.g. 0.3-0.5). This axial frictional force is small compared to the axial electrostatic forces of the motor which are in the range of $\mathrm{mN}$. Therefore friction between gears as a result of the rocking motion is not 
expected to affect motor torque and performance strongly.

\section{FABRICATION}

The fabrication of electrostatic axial gap micromotors, comb drive actuators and curved electrode actuators together with integrated gear mechanisms is based on a seven mask process using polysilicon surface micromachining techniques. The process steps are illustrated in fig. 1. Starting material is a (100) p-type $3 "$ silicon wafer. First a $1 \mu \mathrm{m}$ thick stress reduced silicon nitride layer is deposited by LPCVD. This is followed by the deposition of a 0.5 $\mu \mathrm{m}$ thick LPCVD polysilicon layer. This polysilicon layer is subsequently doped with boron by solid source indiffusion for one hour at $1100{ }^{\circ} \mathrm{C}$. After boron indiffusion the BSG layer is stripped in a buffered HF-solution and the polysilicon is patterned to form the stator poles of the motor and ground planes of electrostatic actuators (mask \#1, fig. 1a). Now a second stress reduced LPCVD silicon nitride layer with a thickness of $0.5 \mu \mathrm{m}$ is deposited which serves as an insulation layer. In this $\mathrm{Si}_{\mathrm{X}} \mathrm{N}_{\mathrm{y}}$ layer contact windows are etched by RIE in a $\mathrm{CHF}_{3} / \mathrm{O}_{2}$ gas mixture in order to make electrical contact to the stator poles and ground planes (mask \#2, fig. 1b). Next a $\mathrm{SiO}_{2}$ layer is grown by PECVD with a thickness of 2 $\mu \mathrm{m}$ which defines the air gap spacing between the stator and the rotor of the micromotor and partly defines the sacrificial layer of the structures (fig. 1c). Locally reductions are etched in this $\mathrm{SiO}_{2}$ layer using a BHF solution to define the circular region on which the rotors will roll (mask \#3, fig. 1d). The ball bearings and slider slots are formed by RIE etching of the $\mathrm{SiO}_{2}$ layer using a $\mathrm{CHF}_{3}$ plasma, RIE etching of the $\mathrm{Si}_{\mathrm{x}} \mathrm{N}_{\mathrm{y}}$ layers using a $\mathrm{CHF}_{3} / \mathrm{O}_{2}$ gas mixture and dry isotropic underetching of the silicon wafer in a $\mathrm{SF}_{6} / \mathrm{N}_{2}$ gas mixture (mask \#4,fig. 1e). After this a $\mathrm{SiO}_{2}$ layer with conformal step coverage is grown by LPCVD from TEOS to define the bearing spacing of the rotor structures (fig. 1f). In the silicon dioxide sacrificial layer anchors for the electrostatic actuators are patterned by etching in BHF (mask \#5, fig. $1 \mathrm{~g}$ ). Now a $6 \mu \mathrm{m}$ thick LPCVD polysilicon layer is deposited that is also doped by boron indiffusion as described before. The boron indiffusion also reduces the residual stress of the polysilicon layer. After stripping the BSG layer in BHF a resistivity of about $3 \Omega$ square is obtained. A $1 \mu \mathrm{m}$ thick PECVD silicon oxide layer is grown that serves as an etch mask for the polysilicon layer and prevents boron outdiffusion in the subsequent annealing step at $1100{ }^{\circ} \mathrm{C}$ for 3 hours in order to reduce stress gradients as a result of the one sided diffusion step. Backside layers are stripped by dry etching. The silicon oxide is patterned by RIE using $\mathrm{CHF}_{3}$ gas and the polysilicon is anisotropically etched using a $\mathrm{SF}_{6}, \mathrm{O}_{2}, \mathrm{CHF}_{3}$ gas mixture [16] (mask $\# 6$, fig. 1h). In order to remove the polysilicon from the slots in which the sliders have to move, an isotropic etch step in a $\mathrm{SF}_{6} / \mathrm{N}_{2}$ gas mixture is needed in addition to the anisotropic etch while other areas are protected by photoresist (mask \#7). After a thorough cleaning procedure the sacrificial layers are etched in concentrated HF for $50 \mathrm{~min}$. This is followed by dilution rinsing in DI water, rinsing in isopropanol and rinsing in cyclohexane while preventing the wafers from drying. Now freeze drying is used to remove the cyclohexane at a temperature of $-10{ }^{\circ} \mathrm{C}$ under a high $\mathrm{N}_{2}$ flow in order to prevent stiction problems [17]. The last step is evaporation of a $1 \mu \mathrm{m}$ thick aluminum backside layer (fig. 1i). The final result is shown in fig. 2 to 10 .

\section{EXPERIMENTAL RESULTS}

First experiments have shown that the micromotors can successfully drive gear trains and slider gear racks resulting in, respectively, torque leverage, and rotational to linear transformation. Up to now no integrated micromechanisms that are driven by electrostatic micromotors have been reported. Also comb drive structures and curved electrode actuators in conjunction with micromechanical mechanisms have been driven electrostatically. Variations in operation characteristics of gears have been observed which are expected to result from the non-conjugate gear teeth profile that has been used. Problems like gear backlash and impact are also noticed which are caused by etching- and bearing clearances. Frictional problems were encountered with large slider structures (up to $2 \mathrm{~mm}$ long). Long sliders could be moved manually by probe needles but did not slide by electrical powering micromotors. It is suggested that stress gradients clamp long slider structures in their bearing slots resulting in frictional forces which are larger than the output force of the motors. Further experimental work is needed to obtain more quantitative results.

\section{APPLICATIONS}

Especially designed devices with gear linkages can be used to investigate tribological properties and system design aspects of micromechanical gear systems. The fabricated devices will be used to explore essential features of these issues. For instance measurements on gear trains that are driven by comb drive structures using a gear rack can be used to obtain information on frictional properties of the gear teeth and bearing. In the same way the frictional properties of sliders can be investigated. Also gear linkages can be used to determine the torque output of electrostatic micromotors by, for example, loading the motor with a spring and measuring the deflection to voltage characteristic. Future applications of integrated actuator systems can be found in areas like, for example, micropositioning, micromanipulation (i.e. pick and place), scanning probe microscopy, information storage and micro robotics. 
(a)

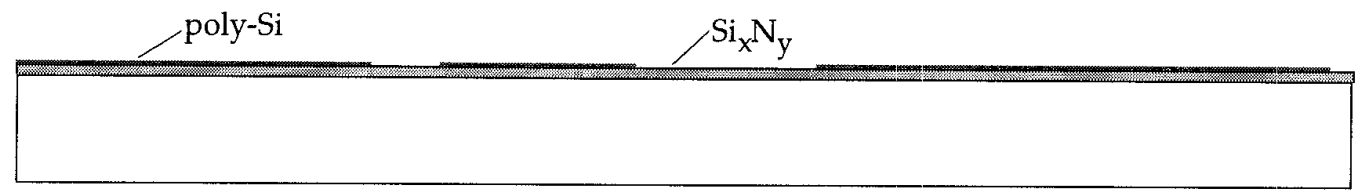

(b)

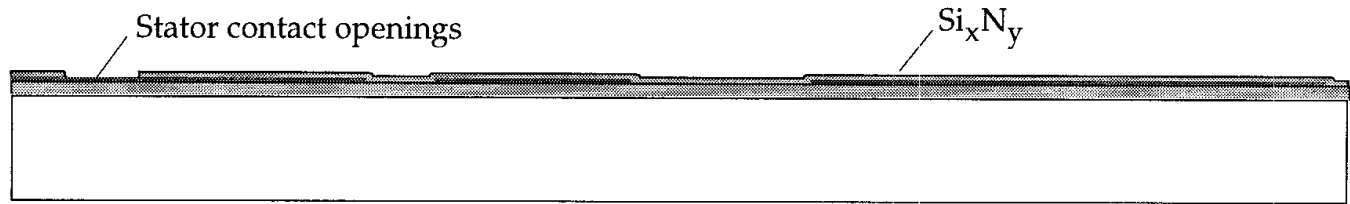

(c)
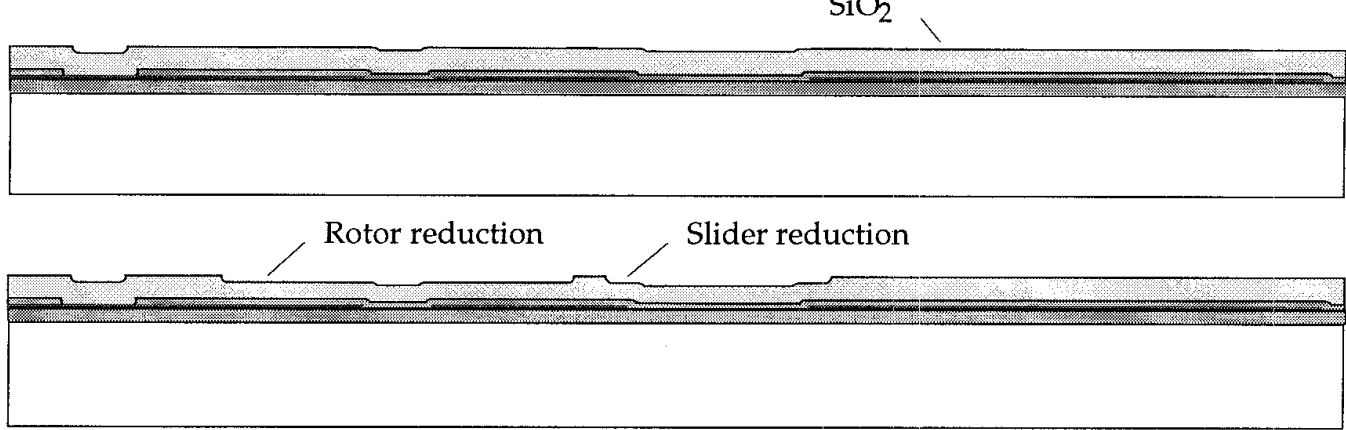

(d)

(e)

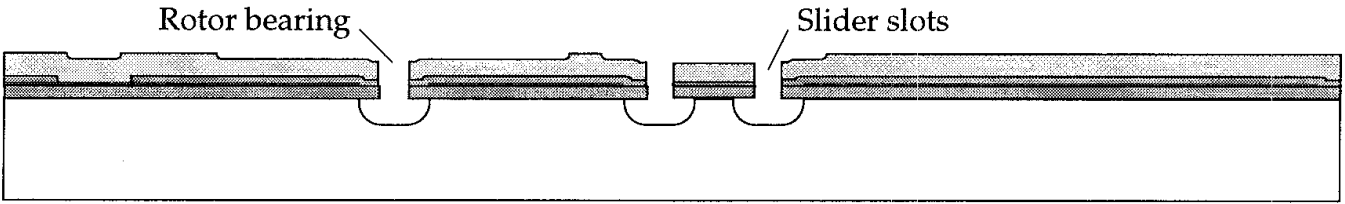

(f)

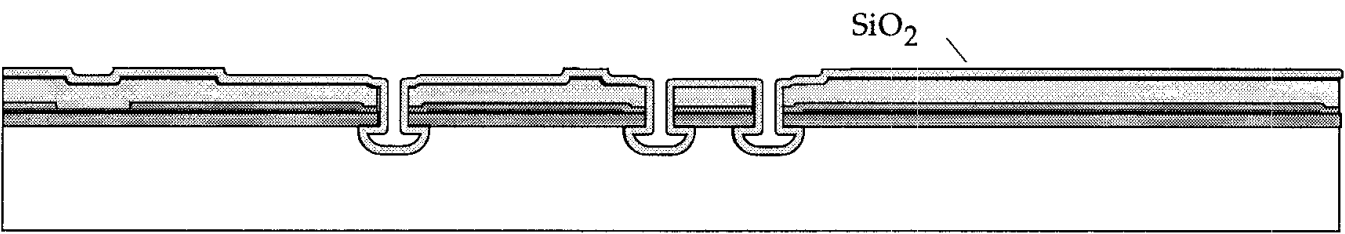

(g)

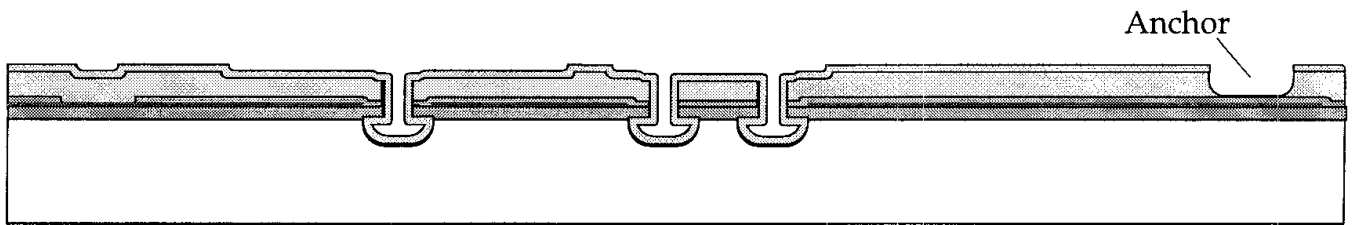

(h)
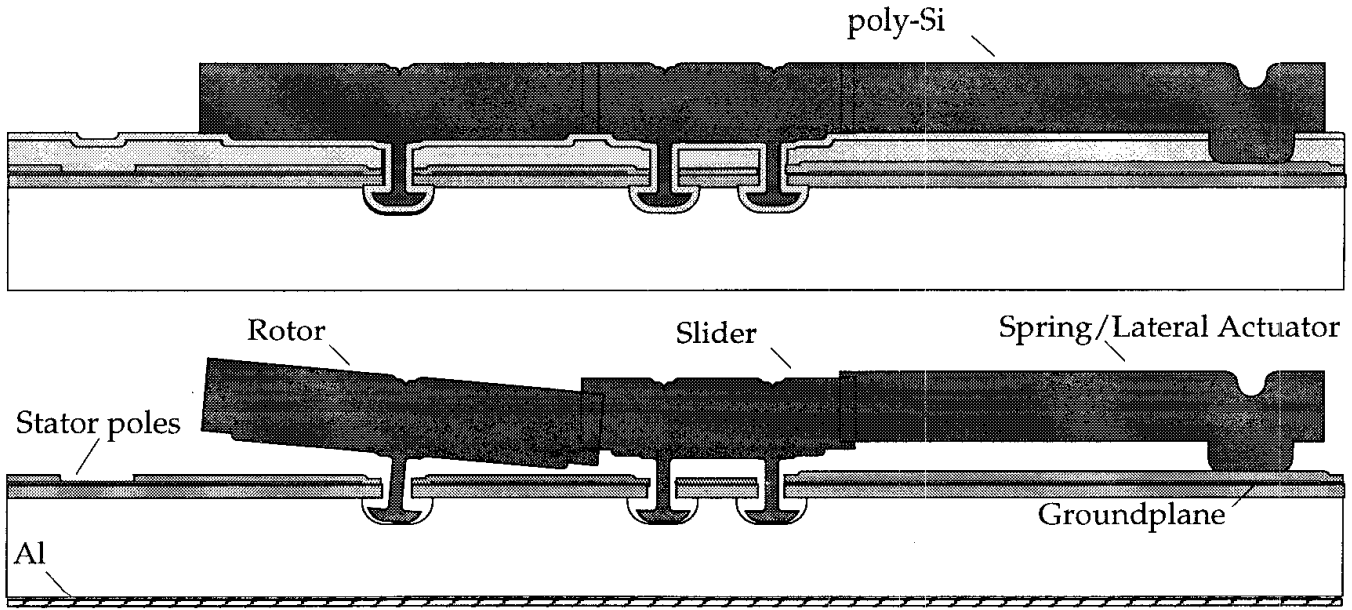

Fig. $1(a),(b),(c),(d),(e),(f),(g),(h),(i)$ Processing sequence for electrostatic actuators with integrated gear linkages. 


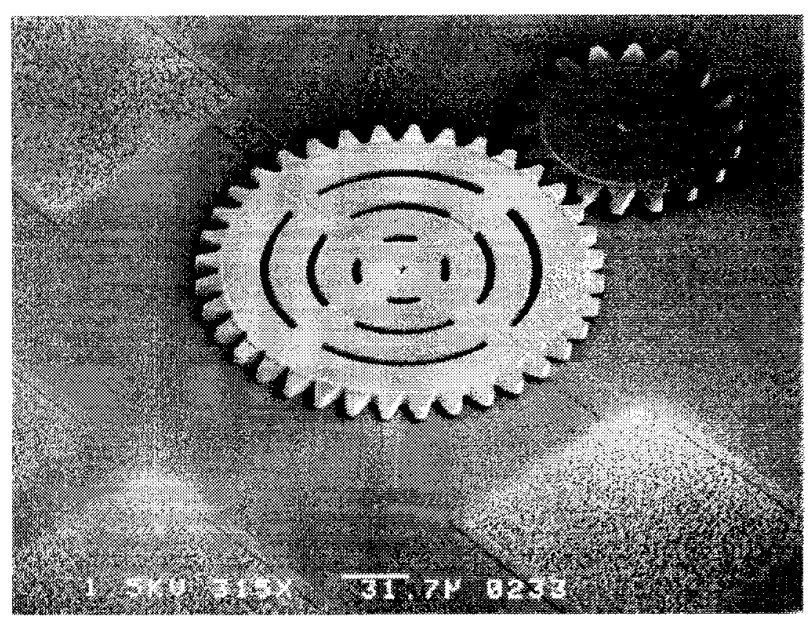

Fig. 2 SEM photograph of an axial gap wobble motor with gear teeth driving a smaller gear. The rotor and the smaller gear have a base radius of respectively $100 \mu \mathrm{m}$ and 50 um.

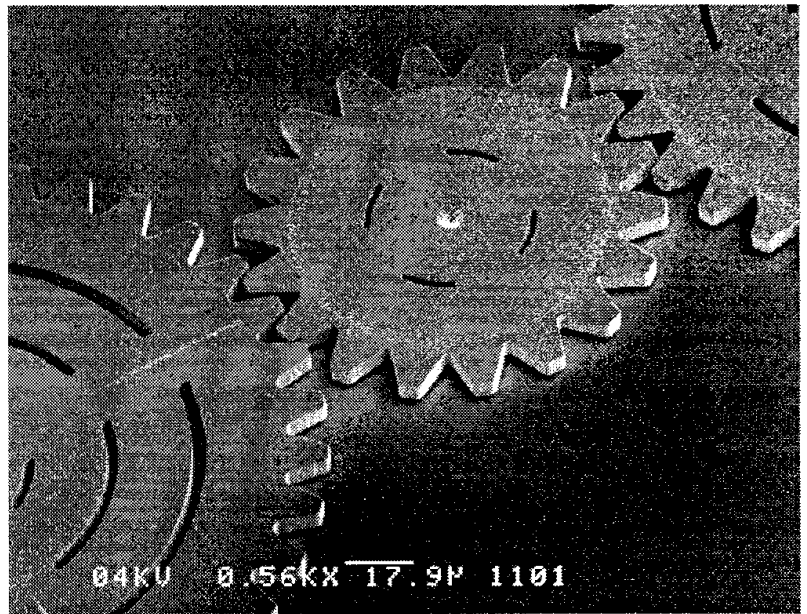

Fig. 3 Close-up of a gear train. The gear teeth have a thickness of $6 \mu \mathrm{m}$, a depth of $11 \mu \mathrm{m}$ and a diametrical pitch of $18.5 \mu \mathrm{m}$.

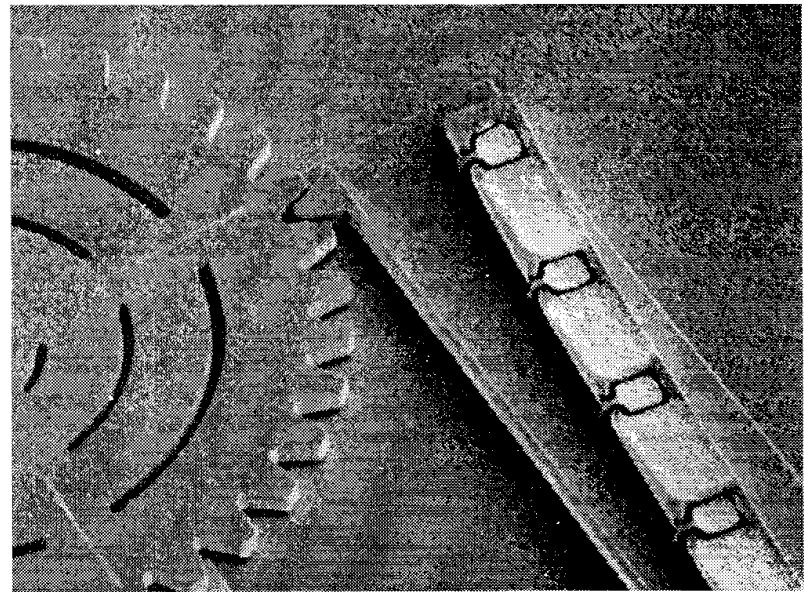

Fig. 4 Curved electrode actuator for fixing gear position.

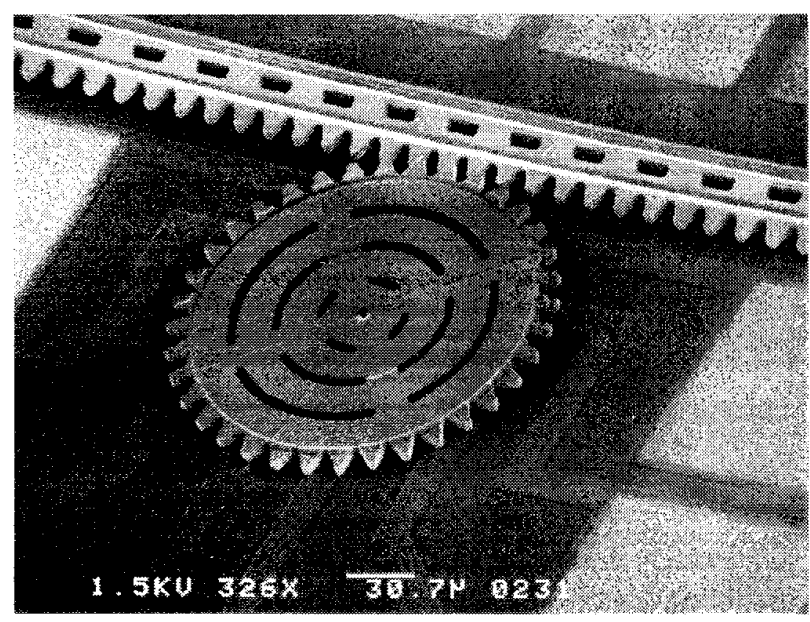

Fig. 5 SEM photograph of an axial gap wobble motor connected to a gear rack resulting in transformation of the rotational into a linear motion

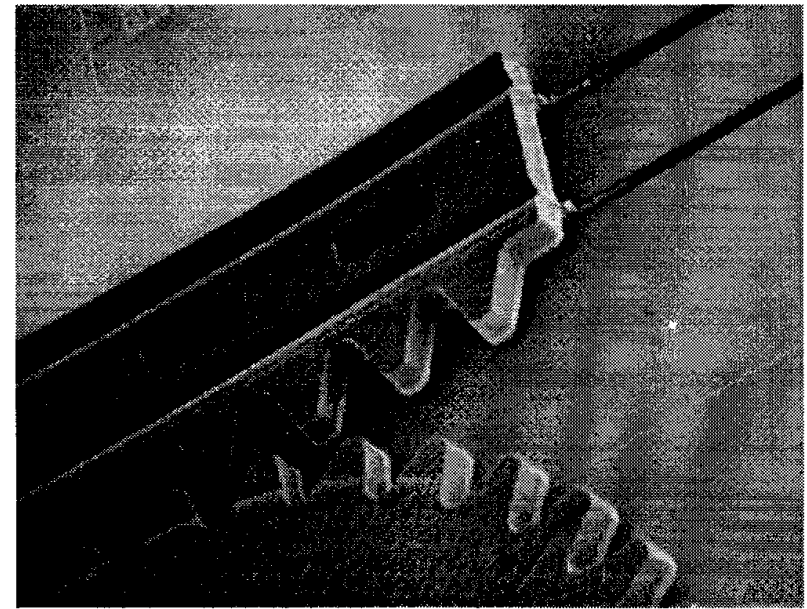

Fig. 6 Close-up of the gear rack. The slider is able to move along slots that have been etched into the wafer.

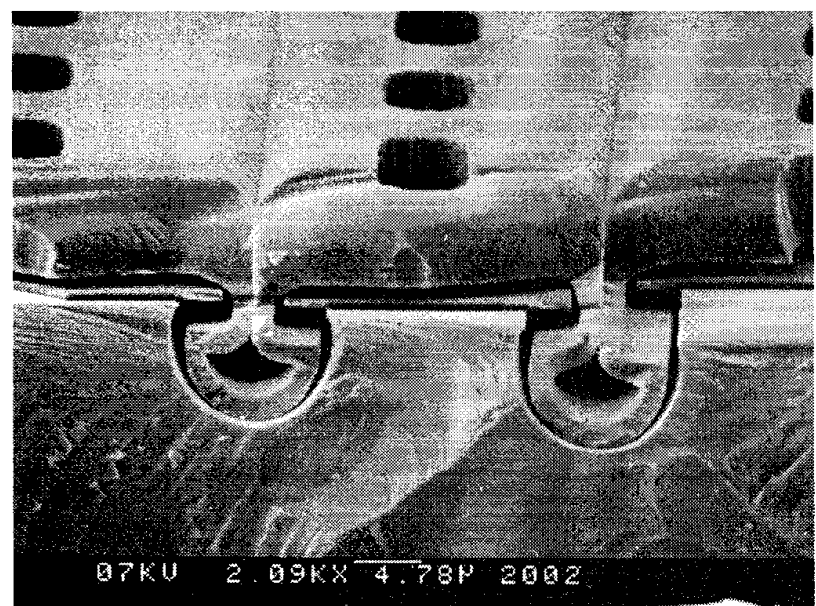

Fig. 7 Cross section of a slider showing the slots and bearing that guide the motion. 


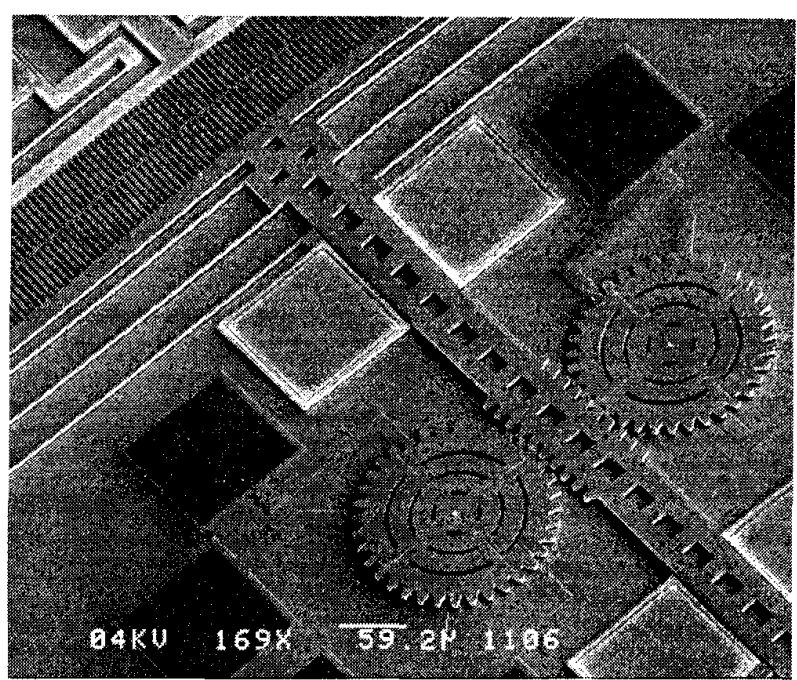

Fig. 8 Motors linked to a gear rack suspended by folded flexures of comb drive actuators. Such structures can be used to measure output torque and motor dynamics.

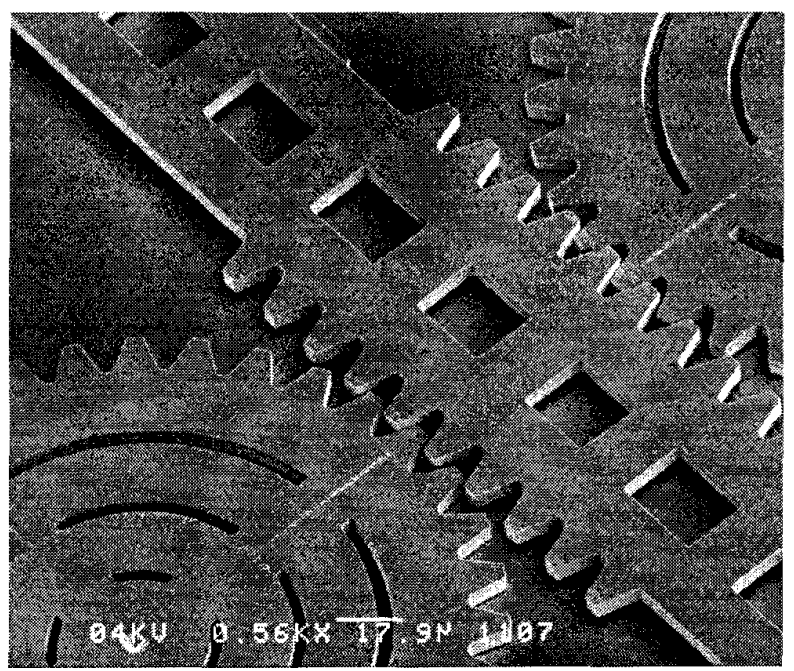

Fig. 9 Close up view of comb drive structure connected to axial gap wobble motors shown in fig. 8 .

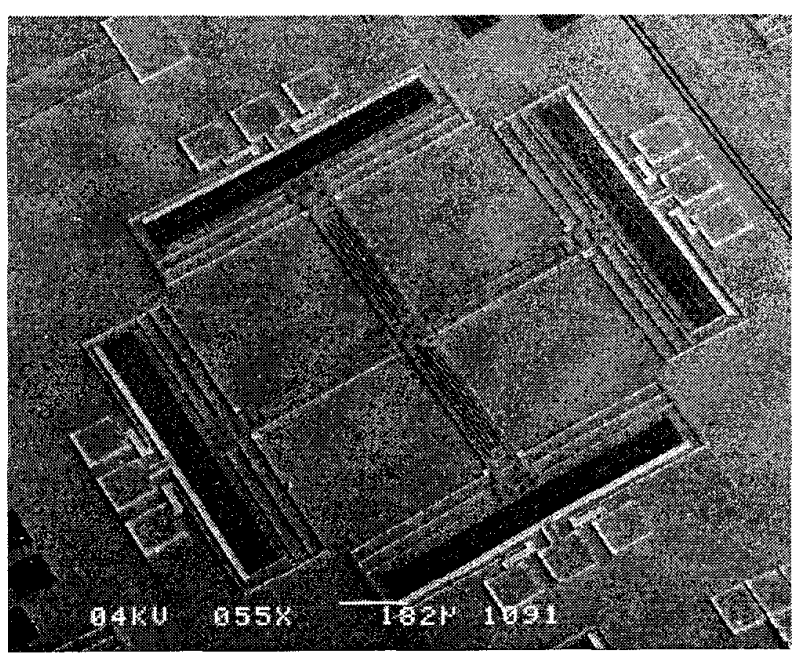

Fig. $10 X Y$-stage fabricated in the same process run.

\section{CONCLUSIONS}

A micromachining process for the fabrication of electrostatic microactuators which are linked with eachother and connected to other movable microstructures by integrated gear linkages has been presented. The fabrication is based on polysilicon surface micromachining and sacrificial layer etching techniques. First experimental results show that electrically powered actuators successfully drive various micromechanisms. The work is a first step towards mechanical power transmission in micromechanical systems. Mechanical power transmission of microactuators may strongly increase the number of useful applications and may lead to new possibilities for microelectromechanical systems.

\section{ACKNOWLEDGEMENTS}

The authors thank Bert Otter and Mark Smithers for making the SEM photographs. This research is sponsored by the Dutch Technology Foundation (STW).

\section{REFERENCES}

[1] Y. Gianchandani and K. Najafi, Proc. IEEE MEMS, Travemünde, Germany, Feb. 4-7, 1992, pp. 141-146.

[2] T.R. Christenson et al, Proc. IEEE MEMS, Amsterdam, The Netherlands, Jan. 29-Feb. 2, 1995, pp. 386-391.

[3] L. Paratte et al, J.Micromech. Microeng., 2 (1992), pp. 221-223.

[4] M.J. Danemanet et al, Proc. IEEE MEMS, Amsterdam, The Netherlands, Jan. 29-Feb. 2, 1995, pp. 55-60.

[5] E.J. Garcia and J.J. Sniegowski, Proc. Transducers '95, Stockholm, Sweden, June 25-29, 1995, Vol. 2, pp. 365-368.

[6] R. Legtenberg et al, Proc. IEEE MEMS, Amsterdam, The Netherlands, Jan. 29-Feb. 2, 1995, pp. 37-42.

[7] R. Legtenberg et al, Proc. MME 95, Copenhagen, Danmark, Sept. 3-5, 1995, pp. 124-127.

[8] R. Legtenberg et al, Proc. Transducers '95, Stockholm, Sweden, June 25-29, 1995, pp. 404-407.

[9] D.W. Dudley, Handbook of practical gear design, McGraw-Hill, New York, 1984.

[10] K.J. Gabriel et al, Sensors and Actuators, A21-A23, 1990 , pp. 184-188.

[11] M. Mehregany et al, Proc. IEEE Solid-State Sensor and Actuator Workshop, Hilton Head Island, SC, U.S.A. June 4-7, 1990, pp. 17-22.

[12] S. Suzuki et al, Proc. IEEE MEMS, Nara, Japan, Jan. 30-Feb. 2, 1991, pp. 143-147.

[13] K. Deng and W.H. Ko, J. Micromech. Microeng., Vol. 2, 1992, pp. 14-20.

[14] H. Zarrad et al, J. Micromech. Microeng., Vol. 3, 1993, pp. 222-224.

[15] U. Beerschwinger et al, J. Micromech. Microeng., Vol. 4, 1994, pp. 95-105.

[16] R. Legtenberg et al, J. Electrochem. Soc., Vol. 142, 1995, pp. 2020-2028.

[17] R. Legtenberg et al, Sensors and Actuators, Vol. A45, 1994, pp. 57-66. 